\title{
THE EFFECT OF TRANEXAMIC ACID, CARBETOCIN AND ARGON PLASMA COAGULATION ON UTERINE INVOLUTION AFTER REPEAT CESAREAN SECTION
}

\author{
Yuliia Slobodian \\ Department of Obstetrics and Gynecology No. $1^{1}$ \\ slobodyaniuliia@gmail.com \\ Oleg Golianovskyi \\ Department of Obstetrics and Gynecology No. $1^{1}$ \\ golyanovskiyoleg@yahoo.com \\ ${ }^{1}$ Shupyk National Medical Academy of Postgraduate Education \\ 9 Dorohozhytska str., Kyiv, Ukraine, 04112
}

\begin{abstract}
Repeat cesarean sections (CS) are associated with additional risks of perioperative complications.

The aim of our study was ultrasound evaluation of uterine involution in women after repeat traditional cesarean delivery and after repeat CS using argon plasma coagulation and prophylactic use of tranexamic acid and carbetocin.

Materials and methods. Prospective cohort study has been conducted on 140 patients who underwent second CS. Group I included 70 women who had repeat CS with the use of argon plasma coagulation and administration of 100 mcg carbetocin after cutting the umbilical cord. Ten minutes before the operation, $15 \mathrm{mg} / \mathrm{kg}$ of tranexamic acid was injected intravenously. Group II consisted of 70 women who had traditional CS, slow intravenous infusion of 10 IU of oxytocin, divided between 5 UI intravenous bolus dose and slow intravenous infusion, was administered after delivery of the baby. A serial ultrasonographic examination was carried out on the $2^{\text {nd }}$ and $5^{\text {th }}$ day of the postpartum period.

Results. A study of the dynamics of changes in uterine body and uterine cavity volume revealed a faster rate of uterine cavity involution in group I compared with group II $(p<0.05)$. In group I on the $5^{\text {th }}$ day in comparison to the $2^{\text {nd }}$ day the mean uterine body volume decreased by $27.75 \%$, in group II - by $20.17 \%$. In group I mean uterine cavity volume declined in three days by $21.09 \%$, in group II - $14.22 \%$. Uterine subinvolution was diagnosed in $3(4.29 \%)$ cases in group I and in 19 (27.14 \%) cases in group II ( $p<0.05)$. Faster uterine involution in group I is probably associated with techniques, that were applied during intraoperative period. In addition, $2.86 \%$ ( 2 cases) from the group I versus $31.43 \%$ (22 cases) from the group II, needed additional uterotonic therapy after surgery (methylergometrine, misoprostol) $(p<0.001)$.

Conclusion. We have found differences in the course of uterine involution in women in group I in comparison with group II, such as significantly smaller uterine length on the $2^{\text {nd }}$ and $5^{\text {th }}$ day, significantly smaller uterine body and uterine cavity volume, faster rates of involution of the uterine cavity during the first 5 days of the postpartum period, thinner anterior uterine wall in the sutured area.

We therefore conclude that complex use of tranexamic acid, carbetocin and argon plasma coagulation appears to be effective to maintain adequate uterine involution after repeat CS and prevent postoperative complications.
\end{abstract}

Keywords: repeat cesarean section, uterine involution, postpartum period, postpartum ultrasound.

DOI: $10.21303 / 2504-5679.2020 .001500$

\section{Introduction}

The rate of cesarean delivery in Ukraine, the same as in other countries, does not tend to decrease and it ranges from $11 \%$ to $29 \%$, reaching even more than $50 \%$ in perinatal centers. Repeat cesarean sections (CS) are associated with additional risks of perioperative complications. Bleeding and uterine atony take the first place among complications of the intraoperative period. The most frequent complications of postoperative period are uterine subinvolution, endometritis, wound suppuration and hematomas $[1,2]$. Fever and endometritis is relatively frequent after CS (1.7-11\%), compared with vaginal delivery (1-2\%) [3].

The rate of uterine involution is one of the important prognostic criteria for the course of the postpartum period. Subinvolution is one of the earliest clinical manifestations of the pathological course of the postpartum period. According to a literature review, the rate of subinvoluted uterus varies from $11 \%$ to $51.5 \%$ of all postpartum pathology [4]. 
Slower process of uterine involution, especially in the first week of the postpartum period, contributes to the risk for developing septic complications.

For this reason accurate and timely diagnosis of uterine subinvolution is very important. Ultrasound of uterine is a useful tool after delivery and is important in facilitating an early detection of postpartum uterine complications. Pelvic ultrasound is accurate, safe, non-invasive and affordable method of controlling of uterine involution. Therefore a serial ultrasound examination of the uterus after delivery is helpful in the assessment of uterine shape, position, size, volume and cavity, as well as in the diagnosis of subinvolution. In the early postpartum period the transabdominal approach is recommended. The uterus naturally regresses during the puerperium, with the most rapid involution occurring during the first week $[5,6]$.

The aim of our study was ultrasound evaluation of uterine involution in women after repeat traditional cesarean delivery and after repeat CS using argon plasma coagulation and prophylactic use of tranexamic acid and carbetocin.

\section{Material and methods}

Prospective cohort study has been conducted on 140 patients who underwent repeat CS between January 2018 and December 2019 at the clinical base of the Department of Obstetrics and Gynecology No 1 Shupyk National Medical Academy of Postgraduate Education (Kyiv Regional Perinatal Center). Group I included 70 women who had repeat CS with the use of argon plasma coagulation and administration of $100 \mathrm{mcg}$ carbetocin after cutting the umbilical cord. Ten minutes before the operation, $15 \mathrm{mg} / \mathrm{kg}$ of tranexamic acid was injected intravenously. Group II consisted of 70 women who had traditional CS, slow intravenous infusion of 10 IU of oxytocin, divided between 5 UI intravenous bolus dose and slow intravenous infusion, was administered after delivery of the baby.

Written informed consent was obtained from all women. The study was evaluated and approved by Shupyk National Medical Academy of Postgraduate Education Ethics Commission (protocol No. 1, 03.01.2017), keeping in view Helsinki declaration.

In both groups Joel-Cohen incision was used, all uterine incisions were low transverse type, double-layer uterine closure was done. All women underwent spinal anaesthesia. All women received prophylactic antibiotics. Interval between CSs in both groups was 2-5 years.

The inclusion criteria were: women after one prior lower segment cesarean section, without any mental disorders or congenital diseases, 39-40 weeks gestation, one live fetus in the uterus, maternal refusal of vaginal delivery, localization of placenta outside the uterine scar.

The exclusion criteria were: preterm or multiple pregnancy, stillbirth, congenital uterine disorders (bicornuate or unicornuate uterus, double uterus), uterine fibroids or oncological diseases, severe concomitant pathology, premature rupture of membranes, varicose veins in the pelvic region, localization of placenta in the uterine scar area.

There was no statistically significant difference in the women's age, social status, parity and health status.

All ultrasound examinations were performed on Kontron Imagic Agile ultrasound machine with the use of transabdominal probe with frequencies ranging from 2.5 to $6 \mathrm{MHz}$ and transvaginal probe with frequencies ranging from 5 to $8 \mathrm{MHz}$.

A serial ultrasonographic examination was carried out on the $2^{\text {nd }}$ and $5^{\text {th }}$ day of the postpartum period. Each woman was examined 2 times.

An abdominal ultrasound scan was carried out on the $2^{\text {nd }}$ and $5^{\text {th }}$ day after delivery in order to assess the rate of uterine involution. Uterine measurements included: 1) the length of the uterus, the distance between the internal cervical os and the top of the uterine fundus; 2) the anteroposterior diameter was measured in the widest part of the longitudinal section, perpendicular to the longitudinal uterine axis - the distance; 3) the uterine width was measured on a transverse section through the uterine body where it appeared to be at its widest [7]. We evaluated the uterine location, contours, echotexture and echogenicity of the anterior wall of the uterus in the sutured area, condition of uterus suture, endometrial contents.

Since recent years, it has been thought that the most objective process of uterine involution can be evaluated in case of monitoring the dynamics of volume change, so we decided to investigate 
this parameter as well. Ultrasound machine automatically calculated the uterine volume based on three orthogonal measurements (the length, the antero-posterior diameter and the width). The same parameters of the uterine cavity were also measured (the length, the antero-posterior diameter and the width).

During ultrasound examination the presence of blood clots in the uterine cavity was taken into account, since these parameters characterize sufficient uterine contractility and postpartum self-purification processes of uterus.

Results are presented as mean \pm standart deviation. Data were tested for normal distribution. Student t-test was used for comparison between groups. Chi-square test was used for comparison between groups as regard qualitative variables. P-value of less then 0.05 was considered as statistically significant. The STATISTICA software version 10 for WINDOWS was used for the statistical calculations.

\section{Results}

All relevant maternal subject characteristics in both study groups were comparable, none previous abdominal surgery, except cesarean section.

In all cases the indication to CS procedure was uterine scar after previous CS. Mean age of women in group I was 34.09 \pm 6.38 (22-38) years, in group II - 36.71. \pm 3.64 (21-36) years. Mean body mass index in group I $27.16 \pm 2.88$, in group II $-27.61 \pm 3.55(p=0.721)$. Interval between CSs in group I was $3.42 \pm 2.06$, in group II $-4.45 \pm 2.62$ years $(p=0.757)$. Mean infant birth weight in group I was 3324.64 \pm 312.37 grams and in group II $-3374.05 \pm 339.15$ grams $(p=0.914)$.

The results are presented in Tables 1-3.

\section{Table 1}

Median characteristics \pm standard deviation of the uterine size (mm)

\begin{tabular}{lcccc}
\hline \multicolumn{1}{c}{ Uterine size } & & Group I $(\boldsymbol{n}=\mathbf{7 0})$ & Group II $(\boldsymbol{n}=\mathbf{7 0})$ & $\boldsymbol{p}$-value \\
\hline Uterus length $(\mathrm{mm})$ & 2nd day & $125.45 \pm 6.73$ & $143.32 \pm 4.58$ & 0.029 \\
& 5th day & $109.54 \pm 7.41$ & $129.48 \pm 6.82$ & 0.049 \\
Uterus width (mm) & 2nd day & $112.91 \pm 6.28$ & $127.25 \pm 6.15$ & 0.105 \\
& 5th day & $97.12 \pm 7.47$ & $115.68 \pm 7.63$ & 0.084 \\
Anteroposterior diameter $(\mathrm{mm})$ & 2nd day & $70.20 \pm 4.03$ & $78.09 \pm 3.71$ & 0.152 \\
& 5th day & $61.09 \pm 3.31$ & $71.65 \pm 6.24$ & 0.137
\end{tabular}

Table 2

Changing of the anteroposterior diameter of the uterine cavity $(\mathrm{mm})$

\begin{tabular}{cccc}
\hline $\begin{array}{c}\text { Anteroposterior } \\
\text { diameter }(\mathbf{m m})\end{array}$ & Group I $(\boldsymbol{n = 7 0})$ & Group II $(\boldsymbol{n}=\mathbf{7 0})$ & $\boldsymbol{p}$-value \\
\hline $2^{\text {nd }}$ day & $7.84 \pm 0.75$ & $10.17 \pm 1.22$ & 0.106 \\
$5^{\text {th }}$ day & $3.25 \pm 1.56$ & $6.35 \pm 1.17$ & 0.114
\end{tabular}

Table 3

Changing of the uterine volume $\left(\mathrm{cm}^{3}\right)$

\begin{tabular}{ccccc}
\hline \multirow{2}{*}{ Group } & \multicolumn{2}{c}{ Uterine body volume $(\mathbf{c m 3})$} & \multicolumn{2}{c}{ Uterine cavity volume $\left(\mathbf{c m}^{\mathbf{3}}\right)$} \\
\cline { 2 - 5 } & $\mathbf{2}^{\text {nd }} \mathbf{d a y}$ & $\mathbf{5}^{\text {th }}$ day & $\mathbf{2}^{\text {nd }} \mathbf{d a y}$ & $\mathbf{5}^{\text {th }} \mathbf{d a y}$ \\
\hline Group I $(n=70)$ & $524.95 \pm 53.12$ & $379.30 \pm 55.62$ & $31.3 \pm 3.6$ & $24.7 \pm 4.4$ \\
Group II $(n=70)$ & $672.09 \pm 51.13$ & $536.58 \pm 52.84$ & $42.2 \pm 4.1$ & $36.2 \pm 3.8$ \\
p-value & 0.047 & 0.042 & 0.047 & 0.049
\end{tabular}


The mean uterus parameters are smaller in group I, and the decreasing trend is faster. In group I mean uterus length decreased in three days by $12.69 \%$, uterus width - by $13.99 \%$, anteroposterior diameter $-12.98 \%$, in group II mean uterus length decreased by $9.66 \%$, uterus width - by $9.10 \%$, anteroposterior diameter - by $8.25 \%$, respectively.

The dynamic determination of uterine volume the most accurate reflects its involution after cesarean section. It should be noted that when evaluating different parameters of uterine involution, from our point of view, the most indicative for diagnostics is the assessment of the dynamics of changing of the uterine volume and the volume of the uterine cavity, especially in the first 5 days of puerperium. We have found a significant difference in the rate of uterine body and cavity volume involution in groups I and II $(p<0.05)$. A study of the dynamics of changes in uterine body and uterine cavity volume (Table 3) revealed a slower rate of uterine cavity involution in group II compared with group I. In group I on the $5^{\text {th }}$ day in comparison to the $2^{\text {nd }}$ day the mean uterine body volume decreased by $27.75 \%$, in group II - by $20.17 \%$. In group I mean uterine cavity volume declined in three days by $21.09 \%$, in group II $-14.22 \%$.

The study confirmed that women in group II had insufficient rates of uterine cavity involution against the background of decreased uterine body volume. Uterine involution in women of group II was due to myometrium, while the size of the uterine cavity had insufficient rates of reverse development, which may increase the risk of inflammatory complications in this group of women. Faster uterine involution in group I is probably associated with techniques, that were applied during intraoperative period.

In 2 cases in group I and in 5 cases in group II small hematomas $(<15 \mathrm{~mm})$ along the suture line were found and were considered as normal. It was seen as a non-vascular mass of mixed echogenicity, anterior to the uterus and posterior to the bladder. Because of they were less than $4 \mathrm{~cm}$ in size, they were considered normal $[8,9]$.

Blood clots were found in the uterine cavity on the $5^{\text {th }}$ day in group I in $4(5.71 \%)$ and in group II in $12(17.14 \%)(p<0.05)$. In 7 cases in group II vacuum aspiration to remove uterine contents was performed.

Uterine subinvolution was diagnosed in $3(4.29 \%)$ cases in group I and in $19(27.14 \%)$ cases in group II $(p<0.05)$.

Mean anterior uterine wall thickness in the sutured area on the $5^{\text {th }}$ day in group I was $15.01 \pm 2.68 \mathrm{~mm}$, in group II $-21.68 \pm 1.73 \mathrm{~mm}(p=0.038)$. Thinner anterior uterine wall in group I could be a result of anti-exudative effect of argon plasma coagulation of uterine suture. The hypoechoic fluid inserts at the scar location tended to be more frequent in group II compared with group I $14(20 \%)$ cases versus $3(4.29 \%)$, respectively, $p<0.05)$. This may be associated with the increased uterine contractility in group I due to the effect of carbetocin and argon plasma coagulation of uterine suture. Though, the hypoechoic stripe within the scar does not mean incomplete healing [10]. The largest changes of the scar occur within the first month after CS, for this reason further observation is required.

In addition, $2.86 \%$ ( 2 cases) from the group I versus $31.43 \%$ (22 cases) from the group II, needed additional uterotonic therapy after surgery (methylergometrine, misoprostol) $(p<0.001)$. Consequently, significantly more patients required additional oxytocics in the second group. Tranexamic acid was given in 20 cases in group II during operation for postpartum hemorrhage treatment.

\section{Discussion}

Obstetric hemorrhage, especially postpartum hemorrhage, is responsible for more than a quarter of all maternal deaths worldwide [11].

The course of the postoperative period and repair process is determined by a significant number of factors, which include: the state of the macroorganism, the surgery technique, suture material, duration of operation, the amount of blood loss. The achievement of adequate intraoperative haemostasis is important in prevention of acute complications after Cesarean delivery. For this reason mmodern obstetrics reveals an indisputable interest in the improvement of the techniques of performing the operation of repeat CS using the electrosurgical technology, modern intravenous hemostatic and uterotonic agents. 
The results of meta-analysis indicate that double-layer unlocked closure is preferable to single-layer locked closure regarding residual myometrium thickness and scar healing ratio [12].

Argon plasma coagulation - is a monopolar noncontact electrosurgical procedure which uses ionized argon gas to conduct electrical current from the probe to the tissue. This method allows cutting tissue with effective hemostasis, has a local antibacterial action and improves local reparative processes. Argon plasma coagulation means less blood loss and less tissue damage, with penetration depth limited to $3 \mathrm{~mm}$. Tissue carbonization is minimal compared to standard electrocoagulation [13]. Argon plasma energy removes the risk of arcing, alternate side burns, lateral heat effects, and surface carbonization is barely visible $[14,15]$ reported in their study that using argon plasma coagulation during CS reduces the amount of wound exudate and helps to improve microcirculation and tissue repair.

Besides the electrosurgery, the use of systemic antifibrinolytic agents, namely tranexamic acid, is of particular importance. It was authenticated that during surgery the haemostatic balance can change toward increased fibrinolysis, leading to coagulopathy and bleeding. Tranexamic acid reduces bleeding by inhibiting the enzymatic breakdown of fibrinogen and fibrin by plasmin and it has been recognized to decrease blood loss and transfusion needs in various elective surgeries and in post-partum haemorrhage [16, 17].

At the same time, uterotonics, agents used to increase myometrial tone and contractility, are the first-line treatment for postpartum hemorrhage. Despite the fact that the oxytocin is the most widely used uterotonic agent, it has some disadvantages. Since oxytocin has a very short plasma half-life (1-6 min), its administration is required not only during surgery but also in the early postoperative period, when most postpartum bleeding occurs.

In addition, intravenous administration requires 40 minutes to reach a steady-state concentration [18]. At the same time carbetocin is devoid of these disadvantages. Carbetocin is a longacting synthetic oxytocin analogue and is characterized by a rapid onset of action and a long halflife (approximately 40 minutes). Uterine contractions occur in less than two minutes after intravenous administration of optimal dosage of $100 \mathrm{mcg}$ [19]. According to the literature data, a single dose of carbetocin has stronger and longer lasting effect and is more economically viable than oxytocin $[20,21]$.

The trials revealed that using timely prophylactic uterotonics could be helpful [22] and that tranexamic acid as an antifibrinolytic drug could help the bleeding [23]. According to recommendations of WHO, 2018 preventive use of carbetocin is associated with a substantial reduction in postpartum haemorrhage, blood transfusion and the use of additional uterotonics when compared with placebo or no uterotonic.

However, the complex effect of the use of argon plasma tissue coagulation in combination with uterotonic and hemostatic agents on the course of the postoperative period of re-cesarean section has not been studied yet.

There are very few studies showing uterine involution after CS. The strengths of our study are following: the research, from the beginning to the end, was conducted by one person; the same person assisted the women during surgery; an explanation of the differences observed between two approaches is provided.

An average uterine size on day 7 after delivery are: length $-129 \mathrm{~mm}$, width - $94 \mathrm{~mm}$, anterior-posterior diameter $-78 \mathrm{~mm}$. Our results show faster uterine involution. This probably can be explained by the use of modern uterotonics and technical support during surgery.

Extensive blood loss causing surgical difficulties could theoretically affect the healing process and uterine involution negatively. In the Cochrane (2016) regarding «Carbetocin versus oxytocin for prevention of postpartum haemorrhage» is concluded that the use of carbetocin is more effective than oxytocin for preventing postpartum haemorrhage [24].

Our findings suggest that complex use of argon plasma coagulation, tranexemic acid and carbetocin has a marked effect on uterine involution.

Of course, there are some limitations of this study: small number of women in both groups, no results of further postpartum investigation and study of possible chronic complications. The present findings of this study are observational and too narrow to draw more comprehensive 
conclusions. We are planning to continue our research in the future with further observation in the delayed postpartum period.

\section{Conclusion}

Ultrasound assessment and comparison of the course of uterine involution in group I in comparison with group II with a significant difference revealed the following characteristics:

1. significantly smaller uterine body length on the $2^{\text {nd }}(125.45 \pm 6.73 \mathrm{~mm}$ vs. $143.32 \pm 4.58 \mathrm{~mm}$, $p=0.029)$ and $5^{\text {th }}$ day after caesarean section $(109.54 \pm 7.41 \mathrm{~mm}$ vs. $129.48 \pm 6.82 \mathrm{~mm}, p=0.049)$.

2. smaller uterine body volume $\left(524.95 \pm 53.12 \mathrm{~cm}^{3}\right.$ vs. $672.09 \pm 51.13 \mathrm{~cm}^{3}$ on the $2^{\text {nd }}$ day, $p=0.047$ and $379.30 \pm 55.62 \mathrm{~cm}^{3}$ vs. $536.58 \pm 52.84 \mathrm{~cm}^{3}$ on the $5^{\text {th }}$ day, $\left.p=0.042\right)$ and the uterine cavity volume $\left(31.3 \pm 3.6 \mathrm{~cm}^{3}\right.$ against $42.2 \pm 4.1 \mathrm{~cm}^{3}$ on the $2^{\text {nd }}$ day, $p=0.047$ and $24.7 \pm 4.4 \mathrm{~cm}^{3}$ against $36.2 \pm 3.8 \mathrm{~cm}^{3}$ on the $5^{\text {th }}$ day, $p=0.049$ ).

3. thinner anterior uterine wall in the sutured area on the 5 th day of the postoperative period $(15.01 \pm 2.68 \mathrm{~mm}$ vs. $21.68 \pm 1.73 \mathrm{~mm}, p=0.038)$.

4. the hypoechoic fluid inserts at the scar location tended to be less often in group I compared with group II - 3 (4.29\%) cases versus 14 (20\%), $p<0.05$.

5. Uterine subinvolution was diagnosed significantly less frequently in group I (3 (4.29\%) cases versus $19(27.14 \%), p<0.05$.

\section{Conflict of interests}

The authors declare that they have no conflicts of interest.

\section{References}

[1] Hung, H.-W., Yang, P.-Y., Yan, Y.-H., Jou, H.-J., Lu, M.-C., Wu, S.-C. (2015). Increased postpartum maternal complications after cesarean section compared with vaginal delivery in 225304 Taiwanese women. The Journal of Maternal-Fetal \& Neonatal Medicine, 29 (10), 1665-1672. doi: http://doi.org/10.3109/14767058.2015.1059806

[2] Nguyen-Lu, N., Carvalho, J. C. A., Farine, D., Seaward, G., Ye, X. Y., Balki, M. (2015). Carbetocin at Cesarean delivery for labour arrest: a sequential allocation trial to determine the effective dose. Canadian Journal of Anesthesia, 62 (8), $866-874$. doi: http://doi.org/10.1007/s12630-015-0375-2

[3] Cunningham, F. G., Leveno, K. J., Bloom, S. L., Spong, C. Y., Dashe, J. S., Hoffman, B. L. et. al. (2014) Williams Obstetrics. New York: McGraw-Hill, 668-671.

[4] Nielsen, T. F., Hökegard, K.-H. (1983). Postoperative cesarean section morbidity: A prospective study. American Journal of Obstetrics and Gynecology, 146 (8), 911-916. doi: http://doi.org/10.1016/0002-9378(83)90963-8

[5] Al-Bassam, A. N. (2009). Uterine involution after term childbirth. Journal of the Faculty of Medicine Baghdad, 51 (1), 8-11.

[6] Bae, H. S., Ahn, K. H., Oh, M. J., Kim, H. J., Hong, S. C. (2012). Potpartum uterine involution: sonographic changes in the endometrium between 2 and 6 weeks postpartum related to delivery mode and gestational age at delivery. Ultrasound in Obstetrics \& Gynecology, 39 (6), 727-728. doi: http://doi.org/10.1002/uog.11069

[7] Shipp, T. D.; Lockwood, C. J., Levine, D. (Eds.) (2016). Ultrasound examination in obstetrics and gynecology. UpToDate. Literature review. Available at: http://www.uptodate.com/contents/ultrasound-examination-in-obstetrics-and-gynecology

[8] diFlorio-Alexander, R., Harris, R. D.; Fielding, J. R., Brown, D. L., Thurmond, A. S. (Eds.) (2011). Postpartum complications. Gynecologic imaging. Philadelphia: Elsevier, 381-398. doi: http://doi.org/10.1016/b978-1-4377-1575-0.10025-8

[9] Rodgers, S. K., Kirby, C. L., Smith, R. J., Horrow, M. M. (2012). Imaging after Cesarean Delivery: Acute and Chronic Complications. RadioGraphics, 32 (6), 1693-1712. doi: http://doi.org/10.1148/rg.326125516

[10] Paliulyte, V., Drasutiene, G. S., Ramasauskaite, D., Bartkeviciene, D., Zakareviciene, J., Kurmanavicius, J. (2018). Is Postpartum Uterine Involution Impacted by Instrumental or Operative Procedures? Ultrasound Study. Open Journal of Obstetrics and Gynecology, 8 (13), 1289-1304. doi: http://doi.org/10.4236/ojog.2018.813131

[11] Say, L., Chou, D., Gemmill, A., Tunçalp, Ö., Moller, A.-B., Daniels, J. et. al. (2014). Global causes of maternal death: a WHO systematic analysis. The Lancet Global Health, 2 (6), e323-e333. doi: http://doi.org/10.1016/s2214-109x(14)70227-x

[12] Stegwee, S., Jordans, I., van der Voet, L., van de Ven, P., Ket, J., Lambalk, C. et. al. (2018). Uterine caesarean closure techniques affect ultrasound findings and maternal outcomes: a systematic review and meta-analysis. BJOG: An International Journal of Obstetrics \& Gynaecology, 125 (9), 1097-1108. doi: http://doi.org/10.1111/1471-0528.15048

[13] Glukhov, E. Iu., Oboskalova, T. A., Stolin, A. V., Spirin, A. V., Butunov, O. V. (2014). Post-cesarean section uterine scar in clinical and experimental settings. Rossiyskiy vestnik akushera-ginekologa, 1, 10-18. 
[14] Madhuri, T. K., Papatheodorou, D., Tailor, A., Sutton, C., Butler-Manuel, S. (2010). First clinical experience of argon neutral plasma energy in gynaecological surgery in the UK. Gynecological Surgery, 7 (4), 423-425. doi: http://doi.org/10.1007/s10397010-0591-2

[15] Oboskalova, T. A., Glukhov, E. J., Butunov, O. V. (2016). Application of the method of broadband radio wave surgery in operative obstetrics. Journal of Obstetrics and Women's Diseases, 65 (2), 38-43. doi: http://doi.org/10.17816/jowd65238-43

[16] Tranexamic Acid 500mg Tablets - Summary of Product Characteristics (2017). Electronic Medicines Compendium. Available at: http://www.medicines.org.uk/emc/medicine/1489

[17] Shakur, H., Roberts, I., Fawole, B., Chaudhri, R., El-Sheikh, M., Akintan, A. et. al. (2017). Effect of early tranexamic acid administration on mortality, hysterectomy, and other morbidities in women with post-partum haemorrhage (WOMAN): an international, randomised, double-blind, placebo-controlled trial. The Lancet, 389 (10084), 2105-2116. doi: http:// doi.org/10.1016/s0140-6736(17)30638-4

[18] Larciprete, G., Montagnoli, C., Frigo, M., Panetta, V., Todde, C., Zuppani, B., Centonze, C. et. al. (2013) Carbetocin versus oxytocin in caesarean section with high risk of post-partum haemorrhage. Journal of Prenatal Medicine, 7 (1), $12-18$. doi: http://doi.org/10.11138/jpm/2013.7.1.012

[19] Cordovani, D., Balki, M., Farine, D., Seaward, G., Carvalho, J. C. A. (2012). Carbetocin at elective Cesarean delivery: a randomized controlled trial to determine the effective dose. Canadian Journal of Anesthesia/Journal Canadien D'anesthésie, 59 (8), 751-757. doi: http://doi.org/10.1007/s12630-012-9728-2

[20] El Behery, M. M., El Sayed, G. A., El Hameed, A. A. A., Soliman, B. S., Abdelsalam, W. A., Bahaa, A. (2015). Carbetocin versus oxytocin for prevention of postpartum hemorrhage in obese nulliparous women undergoing emergency cesarean delivery. The Journal of Maternal-Fetal \& Neonatal Medicine, 29 (8), 1257-1260. doi: http://doi.org/10.3109/14767058.2015.1043882

[21] Pizzagalli, F., Agasse, J., Marpeau, L. (2015) Carbetocin versus Oxytocin during caesarean section for preventing postpartum haemorrhage. Gynecologie Obstetrique \& Fertilite, 43 (5), 356-360. doi: http://doi.org/10.1016/j.gyobfe.2015.03.004

[22] WHO recommendations for the prevention and treatment of postpartum haemorrhage (2012). Geneva: World Health Organization.

[23] WHO recommendations: uterotonics for the prevention of postpartum haemorrhage (2018). Geneva: World Health Organization.

[24] Rosales-Ortiz, S., Aguado, R. P., Hernandez, R. S., Castorena, M., Cristobal, F. L., González, M. C. et. al. (2014). Carbetocin versus oxytocin for prevention of postpartum haemorrhage: a randomised controlled trial. The Lancet, 383, S51. doi: http:// doi.org/10.1016/s0140-6736(14)60314-7 